\title{
ENTRE-LUGARES E IDENTIDADES MONOLÍTICAS: LEITURAS MÚLTIPLAS DE ANZALDÚA EM SALA DE AULA
}

\author{
(The in-between spaces and monolithic identities: \\ multiple readings of Anzaldúa in the classroom)
}

\author{
Dilys Karen Rees ${ }^{1}$ \\ Joana Plaza Pinto ${ }^{2}$ \\ (Universidade Federal de Goiás - UFG)
}

\begin{abstract}
This article presents an analysis of students' answers to discussion questions about the text Tlilli, Tlapalli - the path of the red and black ink by Gloria Anzaldúa. Concepts such as the border and the mestiza (Anzaldúa,), inbetween spaces (Bhabha, 2003), the familiar and the strange (Gadamer, 1999) were used as the analytical base. The results of the study show a multiplicity of reading at the same time in which the students interpreted Anzaldua's border position - both textual and linguistic in-between spaces as well as the in-between space of identity etc. - as strange and different, especially in the textual disruptions present in this important writer.
\end{abstract}

Key-words: Teaching Literature; English Language; Identities

\section{RESUMO}

Este artigo apresenta uma análise de respostas de estudantes a questões de discussão relativas ao texto Tlilli, Tlapalli - the path of the red and black ink de Gloria Anzaldúa (1999). A análise é baseada em conceitos tomados

1. Doutora em Linguística Aplicada/UFMG. Na graduação da Faculdade de Letras da UFG, ministra as disciplinas de Língua Inglesa, História da Língua Inglesa e Literaturas da Língua Inglesa. No programa de Pós-Graduação em Letras e Linguística da UFG, trabalha com pesquisas etnográficas de sala de aula e temas referentes à interculturalidade.

2. Doutora em Linguística/Unicamp. Na graduação da Faculdade de Letras da UFG, ministra a disciplina de Língua, Escrita e Identidade, entre outras. No programa de Pós-Graduação em Letras e Linguística da UFG, trabalha com temas referentes à linguagem, identidade e cultura. 
dos escritos de Anzaldúa, como fronteira e mestiza, do conceito de entrelugar (Bhabha (2003, bem como do conceito de estranho e familiar de Gadamer (1999). Os resultados do estudo mostram uma multiplicidade de leituras, ao mesmo tempo em que a posição fronteiriça de Anzaldúa entre-lugares textuais, linguísticos, identitários etc. - foi interpretada como estranha e diferente nas reflexões dos estudantes, especialmente as rupturas do texto desta importante escritora.

Palavras-chave: Ensino de literatura; Lingua inglesa; Identidades

\section{Introdução}

Integrando o objetivo geral de focar produções linguísticas em contextos multilíngues e sua relação com identidades em processos pós-coloniais, este trabalho analisa a compreensão do entre-lugar, conceito de Bhabha (2003), e da relação entre o estranho e familiar, baseada em Gadamer (1999), na leitura de um texto da chicana Gloria E. Anzaldúa em sala de aula de literatura de língua inglesa. Os conceitos tomados dos escritos de Anzaldúa, como fronteira e mestiza, também apoiaram a análise. Para isso, foram confrontadas questões textuais em Tlilli, Tlapalli - the path of the red and black ink, publicado originalmente no livro Borderlands/La Frontera, coletânea de Anzaldúa originalmente publicada em 1987, e as compreensões de um grupo de estudantes de literatura de língua inglesa sobre tais questões.

As análises mostram uma multiplicidade de leituras, ao mesmo tempo em que a posição fronteiriça de Anzaldúa - entre-lugares textuais, linguísticos, identitários etc. - foi interpretada como estranha e diferente nas reflexões da turma, especialmente as rupturas do texto desta importante escritora de língua inglesa. Revelando alguns elementos para o ensino de literatura de língua inglesa, concluímos que essas análises das respostas apresentadas foram fundamentais para a continuidade dos debates sobre a autora, indicando a necessidade de novas estratégias para os alunos construírem leituras de textos literários, escritos na sua segunda língua. 


\section{Referencial teórico}

É possível fazer um contraponto com os conceitos da filosofia hermenêutica de Gadamer (1999) ao considerarmos as palavras "familiar" e "estranho", que, na filosofia gadameriana, não são formas de avaliar aquilo que nos cerca, mas descrevem a maneira como nos situamos em relação aos eventos que ocorrem. Essas palavras são modos de existência dentro de situações interpretativas que vivemos. O familiar, nessa acepção, é definido existencialmente como uma experiência que nos conforta e nos afirma positivamente. O estranho, por sua vez, não é um problema a ser resolvido ou descartado, mas é uma situação que nos traz sentimentos de desorientação e perda. Para que haja compreensão é preciso que sejamos interpelados pelo estranho, já que da ruptura do familiar, podemos passar à compreensão. O estranho não é algo distante e objetivado, que podemos rotular e remover do nosso percurso, mas é a nossa vivência do próprio momento da ruptura. Na acepção da palavra compreensão, que envolve a produção de novos sentidos e a capacidade de autocompreensão, o estranhamento é essencial. A tarefa hermenêutica consiste em valorizar a tensão entre o familiar e o estranho e não em camuflá-la (cf. Autor, 2008).

Como bem afirma Bhabha (2003:29), o estranho é "a condição das iniciações extraterritoriais e interculturais". Da ruptura do familiar, podemos passar à compreensão. Desta maneira, o estranho não é algo distante e objetivado, que podemos rotular e remover do nosso percurso, mas é a nossa vivência do próprio momento da ruptura. $\mathrm{Na}$ acepção da palavra compreensão, que envolve a produção de novos sentidos e a capacidade de autocompreensão, o estranhamento é essencial.

No mundo constituído linguisticamente, as palavras da nossa primeira língua parecem-nos as únicas adequadas para expressar a nossa vivência. Se a ideologia do monolinguismo é forte no contexto em que aprendemos nossa língua, como o Brasil, é difícil imaginar que as palavras de uma segunda língua sejam apropriadas para mostrar os nossos sentimentos, desejos, vontades como também que sejam 
capazes de interpretar a fundo os eventos culturais em que nos achamos inseridos. Aprender uma segunda língua (L2), no entanto, com o decorrer do tempo, pode-nos "fornecer formas múltiplas de ver e falar sobre as rosas"3 (KRAMSCH, 1993: 2).

É possível que o aprendiz penetre no mundo da outra língua graças à junção dos conceitos já formados pelo aprendiz ao que lhe é trazido pelo mundo linguístico estrangeiro, o que enriquece e amplia a sua vivência. Gadamer (1977:15) afirma que, "somente o apoio da compreensão familiar e comum torna possível o arriscar-se no estranho, o retirar algo do estranho, e assim, o alargamento e o enriquecimento da nossa própria experiência de mundo" ${ }^{4}$ O novo, nesse sentido, é criado a partir da união entre os conceitos que o aprendiz traz à sala de aula e os novos conceitos encontrados ao estudar a segunda língua.

Esse novo sentido foi o principal objetivo dos exercícios analisados neste artigo, que serviram de apoio para que o aluno pudesse lidar com o texto complexo da autora Gloria E. Anzaldúa. Antes de explicar mais sobre a metodologia usada nos exercícios e nas análises, introduzimos um breve perfil da autora e sumariamente alguns aspectos teóricos de sua obra, fundamentais para nossas análises.

\section{Anzaldúa: entre-lugar de identidade e de textualidade}

Poeta, escritora e teórica feminista chicana, Anzaldúa nasceu em Hildalgo, na área do Rio Grande Valley, extremo sul do Texas, em 1942. Anzaldúa afirma, em seus escritos, que esta era uma das regiões mais pobres da fronteira entre México e EUA. Foi trabalhadora rural, especialmente na coleta de algodão, mas conseguiu, com muito apoio da mãe, cursar universidade e se pós-graduar em literatura comparada pela Universidade do Texas (REUMAN \& ANZALDÚA, 2000). Ela foi professora em várias

3. "multiple ways of viewing and talking about roses".

4. "only the support of familiar and common understanding makes possible the venture into the alien, the lifting up of something out of the alien, and thus the broadening and enrichment of our own experience in the world". 
universidades da costa oeste. Lecionou estudos chicanos, estudos feministas e escrita criativa. Além disso, foi importante militante pelos direitos campesinos, pelos direitos das mulheres e pelo debate pós-colonialista e anti-racista nos EUA.

Anzaldúa se denominava uma pessoa na fronteira: na fronteira entre países, na fronteira entre línguas, na fronteira entre culturas, na fronteira entre sexualidades. Em suas próprias palavras Anzaldúa (2005: 704) afirma:

Porque eu, uma mestiza, continuamente saio de uma cultura para outra, porque eu estou em todas as culturas ao mesmo tempo, alma entre dos mundos, tres, cuatro, me zumba la cabeza con lo contradictorio.

Estoy norteada por todas las voces que me hablan simultáneamente.

Como ela afirma, seus textos são eles mesmos fronteiriços, com colagens, mudanças constantes de idiomas (variantes diversas do espanhol, variantes diversas do inglês, nahuatl e outros idiomas indígenas), mudanças constantes de tipos textuais (poesia, prosa, teoria). Anzaldúa é, portanto, reconhecida por confrontar dicotomias, borrando as fronteiras do gênero textual, das línguas e das identidades com base na noção de mestizo, um entre-lugar da identidade e da textualidade. Bhabha (2003: 20) assim define o entre-lugar:

[a]queles momentos ou processos que são produzidos na articulação de diferenças culturais. Esses 'entre-lugares' fornecem o terreno para a elaboração de estratégias de subjetivação - singular ou coletiva - que dão início a novos signos de identidade e postos inovadores de colaboração e contestação, no ato de definir a própria idéia de sociedade.

Articulando textos que são ao mesmo tempo narrativa, autobiografia, poesia e teoria, usando ao mesmo tempo diversas variantes do espanhol, do inglês e o nahuatl - muitas vezes num mesmo texto, e defendendo identidades múltiplas e contraditórias, Anzaldúa se localiza nesse entre-lugar pós-colonial, onde o estranhamento é central, e elaborado como uma "consciência mestiza". Essa consciência 
está refletida em sua prática de escrita, afirmando a "tolerância à ambiguidade", expressão mais apropriada para definir o mestizo - ao mesmo tempo contra a opressão branca ocidental e machista, Anzaldúa afirma estar atravessada por esta cultura.

"Estar nas duas margens ao mesmo tempo" ou "trilhar uma outra rota" são as opções para a mestiza partida e dividida, que vive entre culturas, com pertencimentos múltiplos e "inquietude psíquica”. Anzaldúa é enfática, em vários de seus textos, sobre sua defesa de uma posição múltipla, uma posição que não seja apenas contraposição, um agir que não seja apenas reagir. Reflexiva sobre suas práticas de escrita e sobre suas posições no mundo, Anzaldúa intensifica, performativamente, a idéia de que "o sujeito de fala é aquele que produz um ato corporalmente; o ato de fala exige o corpo.” (Autor, 2007:10).

\section{Metodologia}

Ao estudar uma segunda língua, o aprendiz passa a conhecer, por meio de exercícios e textos pedagógicos, a variedade da segunda língua relacionada à sala de aula, tanto em termos de oralidade quanto em termos da escrita. Na nossa experiência de professoras de literatura, constatamos que ao ler um texto literário, o aluno, com frequência, encontra usos linguístico-textuais que fogem às suas expectativas, levando-o ao estranhamento e à rejeição do texto literário. Kramsch (1993: 130), por sua vez, também constata dificuldades semelhantes na aula de literatura de L2, "a maior dificuldade encontrada pelos aprendizes de língua quando lidam com textos escritos surge da passagem de um modo mais oral para um modo mais literário de expressão". ${ }^{5}$ Acreditamos que é possível usar a distinção usada por Widdowson (1992) entre textos referenciais e textos representacionais e afirmar que grande parte dos textos literários, mesmo em prosa,

5. "the major difficulty encountered by language learners when they deal with written texts stems from the passage from a more orate to a more literate mode of speech". 
é representacional, pois representam um mundo construído no imaginário. O aluno, porém, por ser aprendiz da língua em que os textos literários são escritos, encontra dificuldade para lidar com a característica da representação. Por essa razão, a nosso ver, cabe ao professor criar caminhos por meio de atividades que forneçam ajuda ao aluno para que consiga produzir leituras do texto por si mesmo, evitando, assim, a rejeição do texto literário.

Os alunos, que participaram voluntariamente desta pesquisa, cursavam o quinto período do curso de Letras/Inglês da Universidade Federal de Goiás. No total eram dezesseis alunos que, na sua maioria, faziam a disciplina de literatura em língua estrangeira pela primeira vez. A disciplina, Literaturas em Língua Inglesa I, teve a duração de um semestre. A ementa fornecia os seguintes parâmetros para o conteúdo programático:

Estudo sincrônico ou diacrônico da produção contística e novelística inglesa e norteamericana, canônica e não canônica, assim como das literaturas pós-coloniais dos séculos XX e XXI. Estudo e reflexão de aspectos pedagógicos referentes ao uso do texto literário em sala de aula de língua inglesa.

Nos primeiros dois meses do semestre, os alunos leram cinco contos e, nos dois últimos meses, leram dois romances. Os exercícios sobre um texto específico dessa autora foram feitos em grupos ou pares e não individualmente para que a leitura e a voz do par pudessem servir também de apoio para a produção de uma leitura feita pelos próprios alunos e que não fosse uma mera reprodução das falas das professoras. Usando a terminologia de Gadamer (1977) que já mencionamos, a pergunta/apoio buscava ajudar o aluno a caminhar do seu conhecimento familiar e conhecido para o conhecimento do novo e estranho presente no texto de Anzaldúa.

Enfatizamos que os exercícios não visavam à atribuição de nota, mas pretendiam levar os alunos a discutir o texto. Apontamos que em uma discussão oral em sala, somente os alunos mais desenvoltos falam enquanto os mais tímidos se silenciam. No entanto, ao usar o produto escrito como resultado de uma discussão, as vozes de todos os alunos 
têm mais possibilidades de serem ouvidas. As respostas analisadas neste artigo serviram de base para as aulas seguintes sobre o texto da Anzaldúa, ajudando as professoras a dirigirem a discussão a partir das questões levantadas nas leituras produzidas pelos alunos e não a partir de um repertório extra-sala.

Os alunos foram instruídos para chegarem à primeira aula com o texto já lido e com questões para serem discutidas com uma professora convidada, que ministraria uma aula sobre a autora, Gloria Anzaldúa.

Nessa aula, a biografia da autora foi apresentada, com ênfase na sua identidade chicana. Em termos da construção textual de Tlilli, Tlapalli, apontou-se que as fronteiras do gênero textual são borradas, visto que o texto mistura narrativa, autobiografia e teoria. Discutiuse também a razão do uso das diferentes línguas no texto, nahuatl, espanhol e inglês e a relação com as identidades da autora e dos leitores. Mostrou-se que a obra de Anzaldúa problematiza fronteiras (borderlands), não somente na construção textual, mas também fronteiras psicológicas, espirituais e sexuais.

Nas duas aulas seguintes, os alunos trabalharam em pares ou grupos de três, usando como base para suas discussões perguntas fornecidas pela professora responsável pela disciplina. Como já mencionamos, o objetivo da atividade era, em primeiro lugar, fornecer uma oportunidade para que o aluno pudesse construir a sua leitura do texto de Anzaldúa e, em segundo lugar, as repostas seriam usadas como insumo para discussões futuras. Dessa maneira, os alunos tinham a liberdade de discutir as questões com outros pares e grupos, como também, com a professora. As perguntas ${ }^{6}$ foram:

1. How is Anzaldúa's writing process related to the performativity of the body?

2. How does she show a view of "us" and "them"?

3. In what way does the use of Spanish (without translation) show questions of identity?

6. Como as aulas eram ministradas em inglês e as respostas dos alunos também são em inglês, decidimos manter esta língua no corpo do artigo, colocando as traduções em nota de rodapé, já que a análise será das respostas dos alunos. 
4. How are the words of Nahuatl used? For what purpose are they used?

5. What is "the red and black ink"?7

Os alunos deveriam usar citações do texto de Anzaldúa para comprovar as suas afirmações. Em suma, deveriam argumentar e embasar as suas respostas, não sendo aceitas afirmações sem comprovação.

Havia níveis variados de respostas, mostrando a heterogeneidade da turma. Alguns alunos tinham um domínio maior da língua inglesa e puderam elaborar as suas respostas de forma mais sofisticada, isto é, com menos dificuldades sintáticas e lexicais. Na análise feita neste artigo, no entanto, nos ateremos ao conteúdo das respostas e não faremos uma análise dessas dificuldades.

As questões 1 e 5 requeriam respostas pontuais, pois checavam a compreensão de pontos discutidos na primeira aula. Todos responderam corretamente em maior ou menor grau de detalhamento e discussão. As demais perguntas $(2,3,4)$ exigiam uma compreensão mais analítica, menos pontual do texto. Nessas questões, o aluno poderia demonstrar a sua habilidade de dialogar com os conceitos levantados por Anzaldúa no texto. Optamos por apresentar a análise dessas questões por ofereceram mais escopo para compreender as rupturas na leitura, como também as relações de pertença e as fronteiras que os alunos/leitores enxergaram no texto.

\section{Análise dos Dados}

Os dados analisados serão apresentados em três seções.

7. 1. Como o processo de escrita de Anzaldúa está relacionado à performatividade do corpo? 2. Como ela mostra uma visão de "nós" e "eles"? 3. De que maneira o uso de espanhol (sem tradução) mostra as questões de identidade? 4. Como são usadas as palavras em nahuatl? São usadas para que objetivo? 5. O que é "a tinta vermelha e preta"? 


\subsection{A visão de "nós" e "eles"}

No texto de Anzaldúa, encontramos vários parágrafos que discutem questões relacionadas à arte nas culturas ocidentais europeias e as diferenças com as culturas tribais. Etno-poética, performance xamã e a tirania ocidental no deslocamento estético das artes indígenas são alguns dos temas que Anzaldúa explora. Além disso, a autora também aponta no texto a importância da criação como forma de domar o medo e a escuridão das violências a que ela e o povo chicano são submetidos. Ela afirma que "con imágenes domo mi miedo, cruzo los abismos que tengo por dentro." (ANZALDÚA, 1999: 93).

Vários alunos ao responderem à questão 2 focalizaram o fato de que a autora se identifica como mestiza, havendo diferentes leituras deste termo, como veremos a seguir:

[1] Par F It is so ironic how she denies the European concepts of art even though she is part of it once she calls herself "mestiza" and is writing inside the European university and for its public. She is criticizing the homogeneity of "them" creating homogeneity. In our opinion she does not think from the outside of Western European system, she does not have a dialogical process of writing, so she is not in the borderland when she denies part of herself because she is still thinking in a binary way us/them. It is necessary and urgent that we don't just change the signals (positive and negative) of the oppression of the world. We must promote a real dialogue among the groups and be less 'panfletários'."

Neste trecho, ao examinarmos como Par F definiu o termo mestiza, constatamos que para as alunas Anzaldúa é mestiza por ser uma mistura, aparentemente, de povos com ascendência europeia e povos fora deste universo. Elas afirmam que ela está dentro da universidade europeia e escrevendo, especificamente, para este público 
(...is writing inside the European university and for its public). Como na primeira aula sobre Anzaldúa, foi explicado que ela ministrava aula em uma universidade norteamericana, entendemos que o uso do termo "europeia” pelas alunas se refere às culturas não indígenas, tendo a Europa como matriz. As alunas argumentam, a partir deste fato, que Anzaldúa não está pensando fora do sistema europeu ocidental (...she does not think from the outside of Western European system), pois está inserida neste sistema. Ela está pensando de uma forma binária, não é dialógica e não está na fronteira. As alunas conclamam os leitores do seu texto a serem menos panfletários e a promoverem um diálogo real entre os grupos. Ainda que as alunas não atribuam a Anzaldúa sua compreensão (she is not in the borderland when she denies part of herself), elas expressam a contradição que a própria autora anuncia em sua obra: estar "nas duas margens ao mesmo tempo" e entender que "toda reação é limitada por, e subordinada à, aquilo contra o qual se está reagindo".

A definição do termo mestiza para as alunas é a de mistura. É possível averiguar essa opinião quando as alunas afirmam "she denies part of herself". Dessa forma, as alunas entendem que Anzaldúa é uma mistura de várias "partes" ou culturas, tanto a europeia, quanto a indígena. A autora, então, é mestiça, mas, para as alunas, ela nega a mestiçagem, ao se colocar contra as culturas ocidentais europeias, das quais ela também faz parte. Para entendermos essa visão de mestiçagem, podemos recorrer às palavras de Ribeiro (1995: 68), que, ao discutir a obra colonial de Portugal, assegura, "[s]eu produto real foi um povo-nação, aqui plasmado principalmente pela mestiçagem, que se multiplica prodigiosamente como uma morena humanidade em flor, à espera do seu destino". Essa mestiçagem ocorre pela conquista, pela guerra, pela escravidão, pela colonização. O processo é violento, mas o resultado é um povo mestiço. Novamente, nas palavras de Ribeiro (1995: 73), "[n]ão somos e ninguém nos toma como extensões de branquitudes, dessas que se acham a forma mais normal de se ser humano. Nós não. Temos outras pautas e outros modos tomados de mais gentes." Esse modos, no entanto, incluem e sobrepujam o modo ocidente europeu. Ao misturar, cria-se um outro 
lugar que se desenvolve de forma dialógica, mudando constantemente de características conforme a necessidade do momento. Para DaMatta (1994: 146), “....seria talvez mais produtivo pensar o Brasil com base no número três. Como um sistema tematizado por mediações e não pela famosa 'razão dualista' ". A mediação não significa pautas elaboradas a partir do ocidente europeu ou das "branquitudes", mas sim, o outro lugar que se cria por meio da relação, do diálogo. As alunas, ao não enxergarem a mediação dialógica no discurso da Anzaldúa, rejeitam o que entendem como binário e panfletário. Enquanto Anzaldúa usa mestiza em oposição às segregações raciais na fronteira sul dos Estados Unidos, as alunas pensam "mestiça" como a mistura hierarquizada de raças no Brasil - deixando entrever aquilo que Ribeiro critica: a preocupação em "resgatar" a cultura europeia e sua centralidade para a formação cultural. Ainda que Anzaldúa declare diversas vezes no texto sua heterogeneidade ${ }^{8}$, sua agressividade contra a cultura (ocidental) dominante é interpretada, não como uma retomada necessária da cultura (indígena) dominada, mas como uma reação homogeneizante (She is criticizing the homogeneity of 'them' creating homogeneity).

Para Gadamer (1999: 460), "na compreensão sempre ocorre algo como a aplicação do texto à situação atual do intérprete”. Dessa forma, as alunas do Par F, aplicaram o termo mestizo à compreensão brasileira do termo "mestiço" e trouxeram os argumentos da Anzaldúa para as suas realidades. A leitura, também segundo Gadamer (1999: 262), "é um feitiço que nos solta e nos ata". Nos solta, pois abre novos horizontes ao ouvirmos outras vozes; nos ata, já que quando chegamos aos textos, trazemos os nossos pré-conceitos, resultados da nossa relação de pertença, isto é, da nossa posição como seres sóciohistoricamente situados. Risser (1997: 67) aponta que a neutralidade é impossível e desnecessária para compreendermos um texto, "não é preciso ser neutro para estar sensível à qualidade do novo do texto em que o texto pode dizer algo ao leitor". ${ }^{9}$ As alunas, ao se

8. Um exemplo excelente é o trecho "I write the myths in me, the myths I am, the myths I want to become" (p. 93).

9. "one does not have to be neutral to be sensitive to the text's quality of newness in which the text is able to tell the reader something". 
aterem aos seus conceitos prévios, não puderam ouvir algo novo do texto em relação a essa temática. Nas palavras de Gadamer (1999: 544), "compreender um texto quer dizer compreender a pergunta colocada”. É possível afirmar que, para as alunas, a pergunta colocada por Anzaldúa não ficou clara, fazendo com que elas se fixassem em seus conceitos já elaborados sobre o mestiço e não como o entrelugar dialógico (BHABHA, 2003). Na filosofia hermenêutica, a compreensão é entendida como tendo a característica de um processo visto que os horizontes da compreensão se movem enquanto ocorre o diálogo da pergunta e resposta, visto que o horizonte "é algo no qual trilhamos nosso caminho e que conosco faz o caminho" (GADAMER, 1999:455). Assim, a interpretação das alunas é um dos momentos na construção interpretativa da obra de Anzaldúa.

Outros alunos também focalizaram na questão da mistura ou da mestiçagem:

[2] Par A This point of view is ironic because she thinks Westerners can learn a lot from Indians and tribal cultures, but she is also a Westerner, she is mixed.

Esse par (A) entendeu que Anzaldúa era uma mistura de ocidental e indígena, isto é, os antepassados dela eram indígenas e americanos anglos. Assim, quando a autora problematiza o pensamento ocidental sobre arte, os alunos entenderam que ela problematizava a si mesma por ser, também, ocidental. Por essa razão, a posição seria irônica.

Mais uma vez, como na situação do Par F, no recorte 1, verificamos que os alunos entendem a mestiçagem como sendo aquela existente no Brasil, em que o europeu também é um elemento importante, junto com o africano e o indígena. O europeu, na visão dos alunos, aparentemente é uma unidade única, não havendo diferenciação entre os conceitos ligados às diferentes nacionalidades. Assim como as alunas se referiram a uma suposta "universidade europeia" na qual Anzaldúa daria aulas, esses alunos utilizam o adjetivo "europeu" no sentido de centro hegemônico latino-anglo-germânico (DUSSEL, 1992). O termo para este sentido (centro hegemônico) mais utilizado 
por Anzaldúa no texto é Western, no entanto ela é enfática em utilizar a expressão Anglo para completar o sentido de Western. Além disso, a autora não defende o entendimento de que o mestiço pode ser definido diferentemente conforme a relação de pertença de quem está usando o termo. Assim, o "mestiço" não é, necessariamente, o mesmo de mestizo apesar de serem palavras cognatas em termos linguísticos. Ou seja, enquanto Anzaldúa interpõe o termo mestizo para enfrentar a violência a que indígenas e latinos estão submetidos em território Anglo, os estudantes utilizam "mestiço" para enfatizar a mistura que apaga, em sua síntese sexual e cultural (GONZALES, 1984), a violência a que indígenas e negros foram submetidos em território brasileiro. A trilha para a compreensão do texto de Anzaldúa precisaria passar, então, por uma confrontação desses diferentes termos e dos lugares sociais a que eles pertencem. Prova disso é que, em algumas leituras, houve uma incompreensão de realidades diferentes daquelas do Brasil:

[3] Par B She shows a binary view of us and them when she includes herself into Chicano culture and Mexican cultures, she is a mix of both cultures...Thus she attacks Western culture and remarks her mestice identity and refuses her Anglo background.

Constatamos que os alunos desse par (B) não entenderam o termo chicano e a sua relação com México e a cultura mexicana. Os alunos são de Goiás, um estado no centro do país, e não têm nenhuma experiência com uma situação de fronteira entre dois países. Assim, a questão física de fronteira é estranha para este par, fazendo com que, nesta interpretação do texto de Anzaldúa, não houvesse o movimento da compreensão. Os seus pré-conceitos, isto é, "a realidade histórica do seu ser" (Gadamer, 1999: 416), que constitui o familiar, impediu um diálogo com o novo e estranho.

No entanto, nesse diálogo entre o familiar e o estranho, pode surgir o momento em que significados novos são produzidos, desestabilizando o status quo. Esse tipo de diálogo é uma experiência de limite que "...envolve um entendimento repentino do diferente e 
uma compreensão instantânea da relação entre si próprio e o outro"10 (Kramsch, 1993: 30). A leitura do Par B apresentada no Recorte 3 é o retrato de um momento específico da sua leitura, em que não compreenderam os conceitos ligados ao termo chicano que, por sua vez, é uma identidade de fronteira, não somente em termos geográficos, mas também subjetivos. Chicano, para Anzaldúa, é aquele que está sempre na fronteira, no entre-lugar; a fronteira constitui o seu ser, é sua realidade histórica.

Em seguida, os alunos desse par afirmam que Anzaldúa também é mestiça por ser parte Anglo. Aparentemente, para os alunos, a autora é uma mistura de Chicana, mexicana e Anglo. Retorna-se a um número familiar na identificação da mestiçagem, já que no Brasil, entende-se, frequentemente, que o brasileiro é uma mistura de três raças. Na definição dos alunos, o elemento Anglo é europeu e assim, na argumentação deles, Anzaldúa, ao problematizar o pensamento ocidental, rejeita uma parte de si mesma.

Além das respostas que focalizaram a questão do mestizo, houve outros tipos de respostas:

[4] Grupo E She values her culture and her origins. So, she refers to herself and her chicano culture as us. As the American culture is a culture which wasn't part of her raising in her community it is treated as a strange culture being clearly separated from her chicano culture by referring to it as "them".

O grupo compreendeu que Anzaldúa se vê como chicana e não como americana. Apontamos que desse grupo de três, dois alunos estavam fazendo o terceiro semestre de literaturas da língua inglesa. Como as disciplinas de literaturas de língua estrangeira são semestrais e tem pré-requisito somente de língua, mas não de outra literatura, é possível fazê-las em qualquer ordem. Os dois alunos, então, já tinham mais experiência em lidar com um texto complexo na língua estrangeira

10. “...involves a sudden grasp of difference and an instantaneous understanding of the relationship between self and other". 
e, talvez por esta familiaridade, compreenderam-na de forma melhor. Os seus pré-conceitos já incluíam o conhecimento de como ler textos literários complexos em língua inglesa e como lidar com o estranho nesses textos. Lembramos que no sentido gadameriano, o estranho não é um problema a ser resolvido ou descartado, mas é uma situação que nos traz sentimentos de desorientação e perda. Todavia, a compreensão não é despertada enquanto estiver presa em uma vivência complacente e familiar, pois para que haja compreensão é preciso que sejamos interpelados (GADAMER, 1999:447). Os alunos do Grupo E foram interpelados pelo estranho e puderam passar a compreensão da noção de chicano e da função do espanhol no texto de Anzaldúa, como veremos adiante.

Houve também alunos que elaboraram respostas confusas, que demonstram que a argumentação do texto não foi compreendida:

[5] Grupo C Inspite of she doesn't consider herself as an American, Gloria Anzaldúa makes use of an American view about Western and tribal cultures.

Os alunos entenderam que Anzaldúa não se identifica como americana, mas não entenderam a sua argumentação quando problematiza os pontos de vista ocidental e indígena sobre a arte. Os alunos não compreendem os significados de chicano e de Anglo, já que resumem essas duas posições na palavra American. A heterogeneidade sócio-cultural dos EUA é simplificada e familiarizada nesse termo, que remete a uma nacionalidade homogênea. $\mathrm{O}$ olhar do brasileiro para o outro/americano, o simplifica a uma homogeneidade pasteurizada, em que não há Anglos ou chicanos. Em outras palavras, o aluno utiliza a interpretação familiar, inerente à sua relação de pertença sóciocultural, para compreender conceitos estranhos.

\subsection{O uso da língua espanhola na visão dos alunos}

O uso de espanhol, como em toda a obra de Anzaldúa, ocorre em vários momentos no texto ora usando somente uma palavra em espanhol como "curanderismo", ora escrevendo parágrafos inteiros 
em espanhol. Como um exemplo, citamos o momento em que inicia a descrição do seu processo criativo (Anzaldúa, 2007: 1260). O título dessa seção é em inglês com um subtítulo em espanhol:

\section{Something To Do With the Dark}

\section{Quien canta, sus males espanta. \\ -um dicho}

Logo abaixo dos títulos, há um parágrafo em inglês, seguido por três parágrafos em espanhol. No parágrafo na língua inglesa, a autora descreve o processo de escrita de forma figurativa em que um sapo sai do seu esconderijo, The toad comes out of its hiding place inside the lobes of my brain. It's going to happen again (Anzaldúa, 2007:1260). Nos parágrafos em espanhol, Anzaldúa fala com a musa da escrita chamando-a de bruxa e pedindo que ela venha, Musa bruja, venga. Cubrese com uma sábana y espante mis demônios... (Anzaldúa, 2007:1260). Como ela se propõe a escrever entre línguas, cada língua utilizada mantém o significado próprio do trecho, não havendo tradução dos trechos.

Em relação à língua espanhola encontrada no texto de Anzaldúa, os alunos novamente demonstraram sua heterogeneidade enquanto leitores de um texto complexo, produto cultural de outra localidade sócio-histórica. Ao examinar a questão do uso de espanhol no texto de Anzaldúa, Par D afirma:

[6] Par D Anzaldúa uses Spanish to show where she comes from. Despite she lives in another country she didn't lose her identity and all the time she writes some parts in Spanish to emphasize her Chicana identity.

Para este par, o uso da língua espanhola é uma forma que Anzaldúa usa para mostrar a sua identidade chicana, enquanto ela reside em outro país (in another country). Os alunos, portanto, agrupam as questões de língua e de identidade como subitens do 
grupo organizador maior - a nação. Em outras palavras, no México, era natural que a autora usasse espanhol e fosse identificada como chicana, mas ao viver nos EUA, ela poderia perder essa identidade, pois entende-se que essa identidade era estranha nesse local. A língua espanhola, portanto, passa a ser uma maneira de reforçar questões identitárias em uma situação adversa (she didn't lose her identity; she writes some parts in Spanish to emphasize her Chicana identity). Essa interpretação dos alunos se baseia em uma visão monolíngue e monocultural dos EUA e também na falta de conhecimento sobre a história do território texano, uma parte do México até 1845.

Grupo C apresenta uma interpretação que considera o conceito de mestiza:

[7] Grupo C She keeps Spanish to express that she writes as a person who lives in a Borderland place. She also emphasizes she is a 'mestiza', so she is not going to change the way that she writes just to be understandable by Americans and other people. She is interested in expressing that she also has a Spanish identity.

Para esses alunos, o uso da língua espanhola no texto de Anzaldúa é relacionado ao fato de que ela se situa na fronteira (she lives in a Borderland place), mas na interpretação desse grupo, ao usar o verbo lives in, a fronteira se torna um local geográfico e não um local de subjetividade. Os alunos também afirmam que a autora se coloca como mestiza e que ela escreve em Espanhol para mostrar a sua identidade espanhola (she also has a Spanish identity). A nosso ver, ao usar a palavra Spanish, o aluno intercambiou uma das línguas faladas no México por uma identidade que une aqueles que são falantes dessa língua. Dessa maneira, os alunos afirmam que Anzaldúa usa espanhol no seu texto porque não deseja mudar para ser compreendida pelos americanos e outros (be understandable by Americans and others). Mais uma vez, é possível verificar que os alunos interpretam a partir de uma visão monolíngue e monocultural da nação estadunidense 
em contraposição a outras identidades fixas e monolíticas (a Spanish identity). Os alunos não conseguiram depreender que o lugar de fronteira (borderland) e a mestiza são conceitos que denotam um entrelugar dialógico que se contrapõe a identidades certas e cristalizadas.

Por outro lado, outros alunos interpretaram o uso da língua espanhola no texto como uma maneira de forçar os americanos (Americans) a aprender espanhol e a dar atenção aos chicanos:

[8] Par B The use of Spanish show questions of identity because she had a Latin father and she was born in South Texas, near Mexico. She devoted her attention to chicano women and culture. Being a defensor like that, she had to find a way to get attention, so she put Spanish parts in her text without English translation just to obligate Americans to learn Spanish and understand what she is saying. Usually Americans doesn't give attention to chicanos so in that way Anzaldúa try to get attention to the Spanish culture...

O uso da língua espanhola é interpretado como fazendo parte de um esforço a favor dos chicanos e contra a hegemonia da língua inglesa, interpretada como pertencente aos americanos (to obligate Americans to learn Spanish and understand what she is saying). Segundo os alunos, é uma maneira de focalizar a atenção nos chicanos. Novamente, os alunos não compreenderam o uso da língua espanhola no texto de Anzaldúa como estando vinculado aos conceitos de fronteira e de mestizo e o entre-lugar dialógico. Ao contrário, eles interpretaram esse uso como um momento de confronto entre identidades compreendidas como fixas e homogêneas, isto é, entre a identidade americana e a identidade chicana.

O Grupo E, por sua vez, focaliza as origens de Anzaldúa:

[9] Grupo E Finally, she refuses to translate into English, the Spanish passages to show her origins. She 
could use only one, but she chooses to use both languages to show neither a purely chicano, nor a purely American identity, but a mixture of them all.

Os alunos afirmam que a autora não traduz as passagens em Espanhol para a língua inglesa a fim de mostrar que as suas origens são uma mistura de chicano e americano (but a mixture of them all). Os alunos compreendem que a identidade americana não inclui a identidade chicana ao escreverem, "not a purely American identity". Em outras palavras, segundo os alunos, existe a possibilidade de haver uma identidade americana pura, que está em oposição à identidade chicana, que também pode ser pura, "a purely chicano [identity]". Ao postular a pureza identitária, é possível vislumbrar a homogeneidade tanto de língua quanto de raça como características dessa situação. Assim sendo, os americanos têm características diferentes e em oposição aos chicanos. Os chicanos, nessa visão, não fazem parte de uma identidade maior americana, mas estão fora, em outro local, tanto geográfico, quanto subjetivo. $\mathrm{Na}$ análise dos alunos, Anzaldúa não se situa em nenhuma dessas identidades puras, já que ela é uma mistura. Dessa maneira, na interpretação dos alunos, o texto é um testamento à mistura racial e cultural da autora já que os alunos parecem compreender a mistura como o encontro de identidades em que as duas línguas, ícones das duas identidades, estão presentes.

\subsection{O uso das palavras em Nahuatl na visão dos alunos}

Nahuatl é a língua dos astecas, bem como de outros grupos indígenas do México e dos EUA. No próprio título, as palavras dessa língua são usadas: Tlilli, Tlapalli - The Path of the Red and Black Ink; a segunda parte do título explica a primeira que é escrita em nahuatl. Em outros momentos pontuais do texto, os vocábulos em nahuatl aparecem, geralmente, com uma tradução em nota de rodapé ou com uma explicação no texto. O par F, ao responder à questão 4, afirma: 
[10] Par F The words of Nahuatl are used with translations made by the author herself. She might do it to show that she belongs to this specific culture, what again just stress her identity and how mixed it is, and also the fact that is inside or part of the shamanistic culture. (By the way, we think that these instances of stressing her pieces of identities are another attempt of giving emphasis only to the difference not to the similarities, so it is not dialogical).

Anzaldúa descreve, no seu texto, um estado de perturbação psíquica (psychic unrest) que é a característica de estar situada em uma Fronteira (a Borderland). Os alunos não percebem esta situação ao afirmar que a autora enfatiza somente as diferenças entre as identidades e não as semelhanças (giving emphasis only to the difference not to the similarities), como se as identidades fossem estanques e se encontrassem em termos claros de diferença e semelhança. Na verdade, Anzaldúa nos apresenta uma figura bastante incisiva ao dizer que a vivência da Fronteira é como ter uma farpa de cacto enterrado na sua carne, (It is like a cactus needle embedded in the fles: 1260). Há dialogia, mas é um diálogo que vem da des-ordem, pois tudo se desloca de forma diferente do que seria se as questões identitárias fossem, realmente, controladas por blocos fixos de definições pré-estabelecidas. Assim, a dialogia que os alunos buscam se pauta pela definição do que é semelhante e do que é diferente, já a dialogia apresentada por Anzaldúa se mostra pela perturbação psíquica.

Segundo os alunos desse par, a tradução das palavras de Nahuatl mostra a maneira em que a identidade da autora é misturada (how mixed it is), pois a autora se situa na cultura xamanística e na cultura europeia (cf. Recorte 1). O uso no Nahuatl é uma forma de demonstrar essa mestiçagem. Mais uma vez, os alunos recorrem ao que é familiar da realidade goiana para descrever a mistura no texto de Anzaldúa, isto é, a definição de mestiço enquanto a mistura de raças e não no sentido dialógico proposto por Anzaldúa. 
[11] Par A The Mexican side of Anzaldúa has a heavy influence of Indian culture. She says that making art involves "religious, social and aesthetic purposes". She has shaman religion and believes that the Indians of her family brought their sacred and artistic values into their daily life. This point of view influences her own writings since she thinks that it is "shaman and nahuatl" the ability of the writer to be a shape-changer and transform the storyteller and the listener into something else. Also, the words in nahuatl are used in that way to their exclusive meanings in that language. They have a better meaning in nahuatl than they would have in any other language.

O par A aponta que Anzaldúa recorre às suas raízes indígenas para falar do processo criativo. O escritor é alguém-que-muda-deforma (a shape-changer), mudando a forma não somente do próprio escritor, mas do ouvinte da história também. Assim, as palavras de nahuatl são usadas, segundo os alunos, por causa desse vínculo que Anzaldúa apresenta com a sua identidade não-ocidental. Esse par, portanto, compreendeu que Anzaldúa fala de um âmbito de visão, definido por Gadamer (1999: 452) como o "que abarca e encerra tudo o que é visível a partir de um determinado ponto", diferente do mundo ocidental. Os alunos, na sua situação de aprendizes brasileiros de língua inglesa, puderam encontrar o estranho no texto (shaman and Nahuatl), e a partir dessa ruptura com o familiar da sua vivência, compreender e experimentar o deslocar de horizontes culturais, pois, segundo Gadamer (1999: 447), "a compreensão começa onde algo nos interpela". Os alunos desse par, também, apresentam a opinião que há significados em nahuatl que não podem ser expressos tão bem em qualquer outra língua. $\mathrm{O}$ vínculo da língua com a capacidade humana de interpretar e agir sobre o mundo tanto físico quanto imaginário de formas diferentes e de criar maneiras distintas de viver no mundo, é aparente nessa afirmação dos alunos. Há significados, 
segundo o Par A, que não transitam, facilmente, da língua nahuatl para a língua inglesa ou espanhola, mas lembrando as palavras de Gadamer (1999:649), "cada mundo" humano, por ser estruturado linguisticamente, é "acessível a outros".

Por sua vez, o par E entende que o uso de nahuatl é somente para enfatizar a ligação com a sua cultura de origem.

[12] Par E In her text Anzaldúa uses Nahuatl followed by the translation into English. She could have used only English to write, but instead of doing it, she prefers to use both languages to show her appreciation to her origins and culture.

Diferentemente do Par A, esse par (E) afirma que a autora poderia ter usado a língua inglesa no lugar das palavras de nahuatl. $\mathrm{O}$ uso do nahuatl fica reduzido ao âmbito do afeto ou da lealdade às origens evitando o mundo denso referido no título do texto, Tlilli, Tlapalli, o mundo da tinta vermelha, o sangue, e da tinta preta, a escrita.

\section{Considerações finais}

As análises mostram que as leituras do texto de Anzaldúa são múltiplas, como não poderiam deixar de ser. No entanto, vale a pena destacar neste caso que a ênfase da aula inicial, explicando e localizando a posição fronteiriça de Anzaldúa - entre-lugares textuais, linguísticos, identitários etc. - não foi suficiente para promover o diálogo da turma com as rupturas do texto desta importante escritora de língua inglesa.

Os alunos, ao lerem o texto de Anzaldúa, encontraram-se em um caminho no qual estavam sendo interpelados pelo estranho e o diferente. O caminhar ocorreu em grupo, no sentido de que todos leram o texto e todos tinham a mesma tarefa e responsabilidades como membros da turma. O percurso, no entanto, tem um aspecto 
individual, no sentido de que cada um vivenciou, de forma individual, a tensão do estranho e familiar evidente no texto da autora.

Os pares podem ser agrupados entre: 1. aqueles que comentaram noções como mestiza e fronteira como um entre-lugar, reconhecido como estranho, rompendo as dicotomias e apresentando Anzaldúa como uma autora com pertencimentos múltiplos e à vontade com a contradição; 2. aqueles que comentaram tais noções sempre associadas a identidades homogêneas e estáveis, apresentando Anzaldúa como contraditória e mesmo um pouco confusa. O primeiro grupo reconheceu as estratégias textuais (oposições Indians/ chicano/ Anglo/ Western, usos de diferentes línguas em diferentes contextos etc.) da autora como construtoras do entre-lugar a que Anzaldúa se propõe. $\mathrm{O}$ segundo grupo apontou tais estratégias como contradições internas ao texto e mesmo atenuaram algumas delas (como o uso do nahuatl), reduzindo o sentido subversivo do estranhamento linguístico que Anzaldúa defende.

Seguindo as reflexões de Gadamer (1999) sobre o estranho/ familiar na compreensão de textos, podemos concluir que as interpretações do texto de Anzaldúa encontradas em sala de aula de literatura de língua inglesa são reflexos da complexidade própria do entre-lugar dessa autora (Bhabha, 2003). Retomando a proposta do uso dos exercícios, as respostas que apresentamos neste artigo serviram de base para discussões subsequentes em sala de aula problematizando questões como mestiza versus "mestiço", a fronteira e o entre-lugar. A análise das respostas apresentada neste artigo foi fundamental para a continuidade dos debates sobre a autora, ajudando os alunos a construírem leituras de textos literários, escritos na sua segunda língua.

Recebido em: dezembro de 2012

Aprovado em: março de 2012 joplazapinto@gmail.com dilys_br@yahoo.com 


\section{Referências bibliográficas}

ANZALDÚA, Gloria. "La conciencia de la mestiza /Rumo a uma nova consciência”. Revista Estudos Feministas, Florianópolis, 13, n. 3: 704-719, set.-dez./2005.

ANZALDÚA, Gloria. Borderlands/ La Frontera. $2^{\mathrm{a}}$ ed. San Francisco: Aunt Lute Books, 1999.

ANZALDÚA, Gloria. Tlilli, Tlapalli - the path of the red and black ink. In: GILBERT, S.; GUBAR, S. (Eds). The Norton Anthology of Literature by Women: the traditions in English. New York: W.W. Norton \& Company, 2007: $1255-1262$.

BHABHA, Homi K. O local da cultura. Trad.: Myriam Ávila et al. Belo Horizonte: Editora da UFMG, 2003.

DAMATTA, Roberto. "Para uma antropologia da tradição brasileira (ou: a virtude está no meio)". In: Conto de mentiroso; sete ensaios da antropologia brasileira. Rio de Janeiro: Rocco, 1994, p. 125-149.

DUSSEL, Enrique. "1492 El encubrimiento del outro: Hacia el origen del 'mito de la modernidad'”. La Paz: Plural Editores, 1994. Disponível em: $<$ http://168.96.200.17/ar/libros/dussel/1492/1492.html>. Acesso em: 14/07/ 2009.

GADAMER, Hans-Georg. "The universality of the hermeneutical problem”. In: GADAMER, H.G. Philosophical hermeneutics. Tradução por D. Linge. Berkeley: University of California Press, 1977, p. 3-17.

GADAMER, Hans-Georg. Verdade e método; traços fundamentais de uma hermenêutica filosófica. Traduzido por: F.P. Meurer. Petrópolis: Editora Vozes, 1999.

GONZALEZ, Lélia. Racismo e sexismo na cultura brasileira. Revista Ciências Sociais Hoje, Anpocs, 1984, p. 223-245.

KRAMSCH, Claire. Context and culture in language teaching. Oxford: Oxford University Press, 1993.

PINTO, Joana Plaza. Conexões teóricas entre performatividade, corpo e identidades. D.E.L.T.A., v. 23, n. 1, São Paulo, 2007, p.1-26.

REES, Dilys K. A interculturalidade e a compreensão da peça A Glass Menagerie de Tennessee Williams. In: REES, Dilys K.; MELLO, Heloísa; 
FERREIRA, Maria Cristina (org.). Múltiplas vozes. Goiânia: Editora UFG, 2008, p. 12-29.

REUMAN, Ann E.; ANZALDÚA, Gloria E. "Coming into Play: An Interview with Gloria Anzaldúa”. MELUS, 25, n. 2: 3-45, Summer 2000.

RIBEIRO, Darcy. O povo brasileiro; a formação e o sentido do Brasil. São Paulo: Companhia das Letras, 1996.

RISSER, James. Hermeneutics and the voice of the other; re-reading Gadamer's philosophical hermeneutics. Albany: State University of New York, 1997.

WIDDOWSON, H. Practical stylistics. Oxford: Oxford University Press, 1992. 